\title{
32.1 Gbit/s InverseRZ-ASK-DQPSK modulation with low implementation penalty
}

Tokle, Torger; Serbay, M.; Rosenkranz, W.; Jeppesen, Palle

Published in:

IEEE Lasers and Electro-Optics Society annual meeting

Link to article, DOI:

10.1109/LEOS.2006.279229

Publication date:

2006

Document Version

Publisher's PDF, also known as Version of record

Link back to DTU Orbit

Citation (APA):

Tokle, T., Serbay, M., Rosenkranz, W., \& Jeppesen, P. (2006). 32.1 Gbit/s InverseRZ-ASK-DQPSK modulation with low implementation penalty. In IEEE Lasers and Electro-Optics Society annual meeting IEEE.

https://doi.org/10.1109/LEOS.2006.279229

\section{General rights}

Copyright and moral rights for the publications made accessible in the public portal are retained by the authors and/or other copyright owners and it is a condition of accessing publications that users recognise and abide by the legal requirements associated with these rights.

- Users may download and print one copy of any publication from the public portal for the purpose of private study or research.

- You may not further distribute the material or use it for any profit-making activity or commercial gain

- You may freely distribute the URL identifying the publication in the public portal

If you believe that this document breaches copyright please contact us providing details, and we will remove access to the work immediately and investigate your claim 


\title{
32.1 Gbit/s InverseRZ-ASK-DQPSK Modulation with Low Implementation Penalty
}

\author{
Torger Tokle, Murat Serbay, Student Member, IEEE, Werner Rosenkranz, Member, IEEE and \\ Palle Jeppesen, Member, IEEE.
}

\begin{abstract}
Gbit/s InverseRZ-ASK-DQPSK is experimentally investigated using a new InverseRZ generation method. We demonstrate $<1 \mathrm{~dB}$ upgrade penalty from $21.4 \mathrm{Gbit} / \mathrm{s}$ RZ-DQPSK, and $<2 \mathrm{~dB}$ transmission penalty after one $75 \mathrm{~km}$ fibre span.
\end{abstract}

\section{INTRODUCTION}

Multilevel modulation is a key technology for highly spectral efficient optical communication systems. For some time now, there has been a strong focus on differential quadrature phase shift keying (DQPSK), which offers two bit per symbol. Transmission over transoceanic distances with good performance and high spectral efficiency has already been demonstrated $[1,2]$.

Looking forward from DQPSK, it is clear that adding more symbol levels can increase the spectral efficiency even further. Three bits per symbol has already been demonstrated at 10 Gbaud using a combination of DQPSK with amplitude shift keying (ASK), both with normal return-tozero (RZ) pulse carving [3], and with InverseRZ [4]. Additionally, pure phase modulation has also been used to obtain three bits per symbol [5].

In this work we present a novel method of generating InverseRZ-ASK-DQPSK signals at a symbol rate of 10.7 Gbaud. Unlike previous work with InverseRZDQPSK [4], we generate our InverseRZ-ASK signal without any optical processing. We generate an electrical RZ signal and apply it directly to an Mach-Zehnder (MZ) modulator.

We demonstrate very good receiver sensitivities both for the ASK and DQPSK signals, and show that an upgrade from 2 bits per symbol DQPSK to 3 bits per symbol InverseRZ-ASK-DQPSK can be done with less than $1 \mathrm{~dB}$ OSNR penalty. We transmit our $32.1 \mathrm{Gbit} / \mathrm{s}$ InverseRZASK-DQPSK signal over a $75 \mathrm{~km}$ fibre span with $1.7 \mathrm{~dB}$ penalty.

\section{EXPERIMENTAL SETUP}

The setup is presented in Fig. 1. Light from a distributed feedback (DFB) continuous wave laser is first modulated by a MZ modulator driven with an electrical RZ signal to generate an optical 10.7 Gbit/s InverseRZ-ASK signal with an InverseRZ pulse width equal to $40 \%$ of the sym-

T. Tokle and P. Jeppesen are with COM•DTU Department of Communications, Optics, and Materials, Technical University of Denmark, Ørsteds Plads, Building 345V, DK-2800 Kgs. Lyngby, Denmark (email:tt@com.dtu.dk)

M. Serbay and W. Rosenkranz are with Chair for Communications, University of Kiel, Kaiserstraße 2, 24143 Kiel, Germany

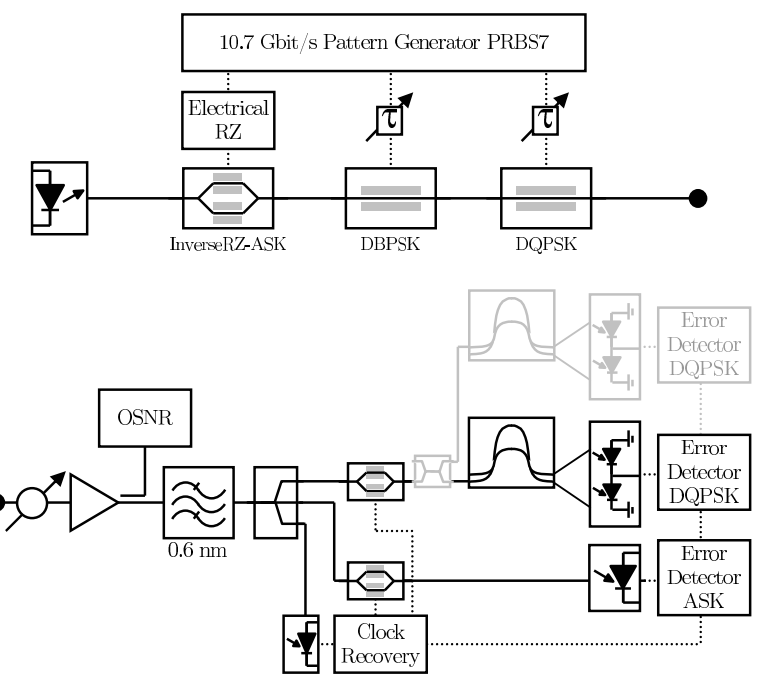

Fig. 1. Experimental setup of InverseRZ-ASK-DQPSK transmitter and receiver.

bol period. The eye diagram of the generated $32.1 \mathrm{Gbit} / \mathrm{s}$ InverseRZ-ASK-DQPSK signal is shown in Fig. 2(a).

DQPSK information is added to the signal using two phase modulators, each driven with a $10.7 \mathrm{Gbit} / \mathrm{s}$ NRZ electrical drive signal, that added $\pi$ and $\pi / 2$ phase modulation, respectively. Thus, a $32.1 \mathrm{Gbit} / \mathrm{s}$ InverseRZ-ASKDQPSK signal is generated at the output. The phase information is aligned such that the phase is constant in the part of the symbol period that has high and constant power.

We use $2^{7}-1$ bit pseudo-random bit sequences (PRBS) for all three data signals, and apply appropriate delays to ensure decorrelation.

In the receiver, we select the desired OSNR by adjusting the input power into an erbium doped fibre amplifier. After tapping off part of the signal for clock recovery and OSNR monitoring, the signal is filtered by a $0.6 \mathrm{~nm}$ optical bandpass filter. Then, we split the signal into two branches, for receiving the ASK and DQPSK information, respectively. In order to improve the receiver sensitivity we include pulse carving in the receiver to select either the amplitude or phase information. This is done by MZ modulators driven by a clock signal at $10.7 \mathrm{GHz}$. Figs. 2(b) and 2 (c) show the signal after the pulse carver in the receiver for the ASK and DQPSK tributaries, respectively.

The ASK receiver simply consists of a photodiode, and the DQPSK receiver consist of a delay demodulator fol- 


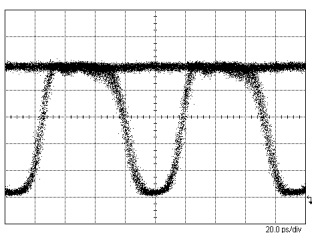

(a) Transmitter output

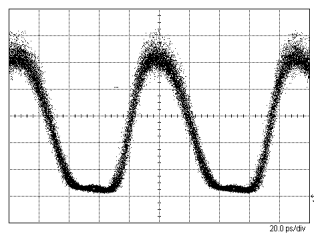

(c) DQPSK after RX pulse

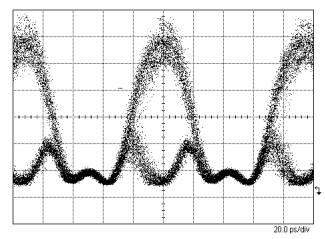

(b) ASK after RX pulse carving

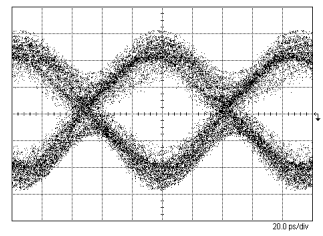

(d) Demodulated DQPSK
Fig. 2. Eye diagram of the signal at various points in the system.

lowed by a balanced photodiode. For receiving the entire DQPSK signal simultaneously, two pairs of demodulators/balanced photodiodes are required. Here we measure the two DQPSK tributaries one after the other and thus used only one receiver. The demodulated DQPSK signal is shown in Fig. 2(d).

We measure the bit error rate (BER) for all tributaries. For DQPSK, we program the error detector with the expected pattern, as precoding was not used for this experiment.

\section{BACK-TO-BACK PERformanCe}

We quantify the signal quality as the optical signal to noise ratio (OSNR) required for a bit error rate of $1.0 \times 10^{-9}$. All tributaries are measured one after the other.

First, we consider a simple $21.4 \mathrm{Gbit} / \mathrm{s}$ RZ-DQPSK system, which we use as our reference system. We generate a DQPSK signal simply by bypassing the ASK parts of the transmitter and receiver. The resulting BER versus OSNR is presented in Fig. 3. We find that an OSNR of $21.6 \mathrm{~dB}$ is required for a BER of $1.0 \times 10^{-9}$. This is a little high compared a normal DQPSK system, since we are using two phase modulators.

We then find the OSNR requirements for our $32.1 \mathrm{Gbit} / \mathrm{s}$ InverseRZ-ASK-DQPSK signal to be $22.5 \mathrm{~dB}$, thus we only have a penalty of $0.9 \mathrm{~dB}$ OSNR for increasing the bit rate by $50 \%$.

The inset in Fig. 3 shows the optical power spectrum of $21.4 \mathrm{Gbit} / \mathrm{s} \mathrm{RZ-DQPSK}$ and $32.1 \mathrm{Gbit} / \mathrm{s}$ InverseRZ-ASKDQPSK. We clearly see that the spectral width of the two formats is almost identical, despite the increase in the number of symbol levels.

\section{TRANSMISSION EXPERIMENT}

To verify that the InverseRZ-ASK-DQPSK modulation format is suitable for optical communication systems, we set up a transmission experiment where we transmitted the

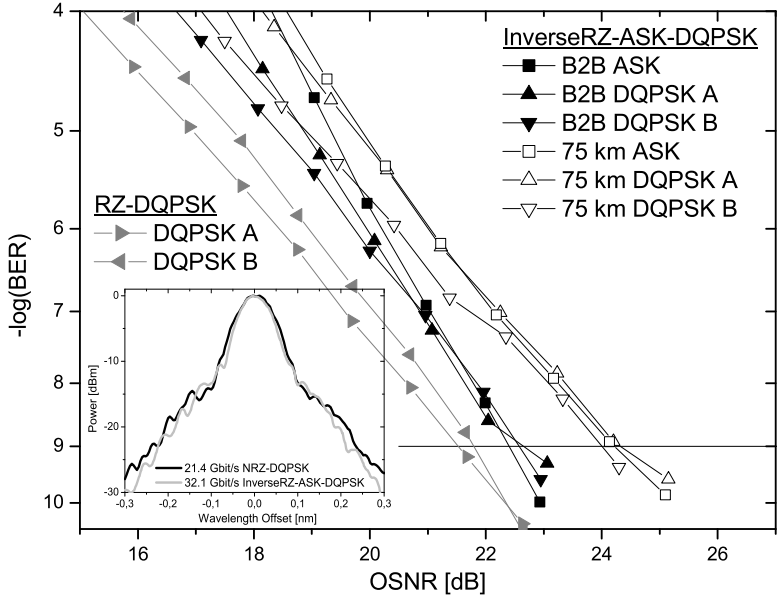

Fig. 3. Bit error rate measurements in the back to back configuration and after transmission over $75 \mathrm{~km}$ SMF.

$32.1 \mathrm{Gbit} / \mathrm{s}$ signal over a fibre span consisting of $75 \mathrm{~km}$ standard single mode fibre (SMF) and $13 \mathrm{~km}$ dispersion compensating fibre (DCF). The dispersion of the fibre span is $17 \mathrm{ps} / \mathrm{nm} / \mathrm{km}$ and $-100 \mathrm{ps} / \mathrm{nm} / \mathrm{km}$, respectively. We measured the BER of the signal after transmission in the same manner as in the back to back investigation. The results are presented in Fig. 3, where we see that an OSNR of $24.2 \mathrm{~dB}$ is required for a BER of $1.0 \times 10^{-9}$ after transmission. Thus, we see a penalty of $1.7 \mathrm{~dB}$ compared to the back-to-back case.

\section{Conclusion}

We have presented a 10 Gbaud transmission experiment using 32.1 Gbit/s InverseRZ-ASK-DQPSK with 3 bits per symbol. A simple InverseRZ generation method is used, and compared to $21.4 \mathrm{Gbit} / \mathrm{s}$ RZ-DQPSK, our signal requires only $0.9 \mathrm{~dB}$ higher OSNR. We successfully transmit this signal over a $75 \mathrm{~km}$ fibre span.

\section{ACKNOWLEDGMENT}

T. Tokle thanks the The Danish Council for Strategic Research for funding the MultiSpeed project.

\section{REFERENCES}

11] T. Tokle, C. R. Davidson, M. Nissov, J.-X. Cai, D. G. Foursa, and A. Pilipetskii, "6500 km transmission of RZ-DQPSK WDM signals," Electron. Lett., vol. 40, no. 7, pp. 444-445, Apr. 2004.

2] S. L. Jansen, D. van den Borne, A. Schöpflin, E. Gottwald, P. M. Krummrich, G. D. Khoe, and H. de Waardt, " $26 \times 42.8 \mathrm{Gbit} / \mathrm{s}$ DQPSK transmission with $0.8 \mathrm{bit} / \mathrm{s} / \mathrm{Hz}$ spectral efficiency over $4,500 \mathrm{~km}$ SSMF using optical phase conjugation," in ECOC'05, Sept. 2005, paper Th4.1.5, post-deadline paper.

[3] T. Tokle, M. Serbay, Y. Geng, J. B. Jensen, W. Rosenkranz, and P. Jeppesen, "Penalty-free transmission of multilevel $240 \mathrm{Gbit} / \mathrm{s}$ RZ-DQPSK-ASK using only $40 \mathrm{Gbit} / \mathrm{s}$ equipment," in $E C O C^{\prime} 05$, Sept. 2005, paper Th4.1.6, post-deadline paper.

[4] T. Miyazaki and F. Kubota, "Superposition of QPSK over inverse-RZ for $3 \mathrm{bit} /$ symbol modulation-demodulation," IEEE Photon. Technol. Lett., vol. 16, no. 12, pp. 428-429, Dec. 2004.

[5] M. Serbay, C. Wree, and W. Rosenkranz, "Experimental investigation of RZ-8DPSK at $3 \times 10.7 \mathrm{~Gb} / \mathrm{s}$," in LEOS'05, pp. $483-$ 484, Oct. 2005, 